Onen, H., Farooq, S., Akyol, N., Ozaslan, C. (2020): Seed dormancy differences among common ragweed (Ambrosia artemisiifolia L.) populations distributed in different climatic regions of Turkey. Agriculture and Forestry, 66 (3): 169-182.

DOI: $10.17707 /$ AgricultForest.66.3.14

\author{
Huseyin ONEN, Nihat AKYOL ${ }^{1}$, \\ Shahid FAROOQ ${ }^{2}$, Cumali OZASLAN ${ }^{3}$
}

\title{
SEED DORMANCY DIFFERENCES AMONG COMMON RAGWEED (AMBROSIA ARTEMISIIFOLIA L.) POPULATIONS DISTRIBUTED IN DIFFERENT CLIMATIC REGIONS OF TURKEY
}

\begin{abstract}
SUMMARY
Common ragweed (Ambrosia artemisiifolia L.) is an allergenic invasive weed rapidly expanding its distribution range throughout Europe. Seed dormancy is among the most important seed adaptation traits, helping colonizing plants to avoid adverse environmental conditions. Furthermore, knowledge of seed dormancy enables to predict the seed germination timing of species and enforce specific management practices at suitable times. This study was aimed at determining the seed dormancy differences among different common ragweed populations distributed in two distinct regions of Turkey (i.e., eastern and western parts of the country). The seeds of all populations were extremely dormant (80.50-96.71\% dormancy). The populations distributed in western part of the country were more dormant than eastern populations.

Mechanical scarification and cold-wet stratification at $4{ }^{\circ} \mathrm{C}$ for 2,3 and 4 weeks were tested to infer their potential in releasing seed dormancy. Cold-wet stratification proved effective in releasing seed dormancy; however, populations differed in the stratification time required for seed dormancy release. Overall, eastern populations became non-dormant with lesser stratification time (i.e., 2 weeks), while western populations took longer stratification time to become completely non-dormant. Mechanical scarification with sandpaper also released seed dormancy and all populations behaved similar for this technique. This knowledge can be used to predict the germination timing of different populations distributed in two distinct regions of the country. Furthermore, the results can also be utilized in implementing effective management strategies at the proper time.

Keywords: Common ragweed, Seed dormancy, Populations, Cold-wet stratification, Mechanical scarification.

\footnotetext{
${ }^{1}$ Huseyin Onen, (corresponding author: onenhuseyin@gmail.com), Nihat Akyol, Gaziosmanpasa University, Tokat, TURKEY.

${ }^{2}$ Shahid Farooq, Department of Plant Protection, Harran University, Sanliurfa, TURKEY.

${ }^{3}$ Cumali Ozaslan, Department of Plant Protection, Faculty of Agriculture, Dicle University, Diyarbakır, TURKEY.

Notes: The authors declare that they have no conflicts of interest. Authorship Form signed online. 


\section{INTRODUCTION}

Common ragweed (Ambrosia artemisiifolia L.) is a notorious invasive plant species readily becoming naturalized throughout Europe. The species has successfully colonized almost all of temperate Europe, while its distribution is limited in areas having relatively high temperatures at the start of common ragweed (ragweed hereafter) growing season (Essl et al., 2015). Ragweed negatively affects biodiversity and its pollens are one of the major sources of seasonal allergies for people (Zemmer et al., 2012; Essl et al., 2015; Ozaslan et al., 2016). Moreover, it is also a noxious weed of different arable crops like sunflower, soybean, maize etc. in several regions of the world (Fumanal et al., 2008; Essl et al., 2015; Ozaslan et al., 2016; Önen, 2015). Therefore, ragweed has been considered among the 100 worst invasive species of Europe (DAISIE, 2016). The extensive distribution of the species along roadsides, non-agricultural areas and ruderal habitats is also observed throughout its invasion range (Fumanal et al., 2008; Essl et al., 2015; Ozaslan et al., 2016). Ragweed produces enormous amounts of seeds, which result in rapid range expansion soon after introduction to new geographic regions. Seeds germinate in late spring and germination is stopped with rise in soil temperature (Essl et al., 2015).

Seed dormancy is an important adaptive trait helping plant species to avoid adverse environmental conditions and promotes persistence in the soil seed bank (Willemsen and Rice, 1972). The dispersion of invasive plant species over time can be maximized by seed dormancy (Mandak and Pysek, 2001; Richardson and Kluge, 2008). The persistence of ragweed in soil seed bank requires a dormant period immediately after seed dispersal (Dinelli et al., 2013). Dormant period helps the plant species to avoid adverse environmental conditions and ensures germination in the next growing season if dormancy is broken. It has been well documented that ragweed seeds exhibit both primary and secondary dormancy (Bazzaz, 1970; Willemsen and Rice, 1972; Baskin and Baskin, 1980; Essl et al., 2015). Primary dormancy can be broken by cold-wet stratification at $4^{\circ} \mathrm{C}$ for 2 weeks (Pickett and Baskin, 1973; Baskin and Baskin, 1980; Fumanal et al., 2006). However, different regional findings suggest the existence of huge variation in ragweed seeds for dormancy and germination among different populations or even within the same population (Willemsen and Rice, 1972; DiTommaso, 2004; Essl et al., 2015). These variations allow invasive plant species like ragweed to persist under a wide range of environmental conditions (Li and Feng, 2009; Eslami, 2011). Seed dormancy helps the colonizing and colonized populations to persist under a specific set of environmental conditions with varying seasonality across different regions. Seed dormancy also excludes the extinction risks and provides opportunities for adaptive divergence.

Different biotic or abiotic factors (external or internal to the seed coat) induce seed dormancy in plant species (Battla and Benech-Arnold, 2007). The seed dormancy status of the seeds continuously fluctuates and reaches to maximum or minimum at different times (Battla et al., 2004). The fluctuations in seed dormancy status hamper the management efforts implemented against 
weedy and invasive species through unusual patterns of seedling emergence (Battla and Benech-Arnold, 2007). Hence seed dormancy knowledge is of prime importance for understanding biology and ecology of the species as well as for predicting seedling emergence (Battla and Benech-Arnold, 2007; Gioria and Pyšek, 2017). The development of management strategies against invasive or weedy plant species requires sound knowledge of seed dormancy (Brownsey et al., 2013).

Ragweed is distributed in three distinct regions in Turkey (i.e., Black Sea, Marmara and Inner Anatolia), which have different climates (Onen et al., 2014, 2015, 2016; Ozaslan et al., 2016). The species has started to incur losses to crop production (Onen et al., 2016; Ozaslan et al., 2016) and recently pollens of the species have been observed in various regions of the country (Farooq et al., 2016; Celenk and Malyer, 2017). Moreover, it has been reported that species is tolerant to various abiotic stresses and invasion will be accelerated in the country in the future (Onen et al., 2017). Hence understanding differences among seed dormancy of different populations distributed in distinct regions is essential for development and enforcing site-specific/region-specific management practices.

Although exhaustive work has been done to understand the seed dormancy in ragweed across different geographic regions of the world, variations among different populations have merely been explored at regional scales. Moreover, the studies have largely focused on the cold-wet stratification for 2 weeks only, while different timings have rarely been explored for different populations. Moreover, seed dormancy in ragweed is due to weak embryo and resistance offered by the hard seed coat; however, mechanical scarification has never been explored. This study was therefore designed to explore the seed dormancy differences among ragweed populations distributed in Marmara (Western part) and Black Sea (Eastern part) regions of Turkey. The results will help to understand the biology and ecology of different populations, predict seedling emergence and enforcement of management options at correct/suitable timings for effective management of the species.

\section{MATERIAL AND METHODS}

Study area

The study area lies in Turkey, which is a diverse country situated between $25^{\circ} 40^{\prime}$ to $44^{\circ} 48^{\prime} \mathrm{E}$, and $35^{\circ} 51^{\prime}$ to $42^{\circ} 06^{\prime} \mathrm{N}$. The total area of the country is 814,578 $\mathrm{km}^{2}$. Out of the total area, 97 and $3 \%$ is located in Asia and Europe, respectively. The country is divided into seven distinct geographical regions namely: Black Sea, Eastern Anatolia, South Eastern Anatolia, Mediterranean, Aegean, Marmara and Inner Anatolia. The ragweed populations included in the study were distributed in Black Sea and Marmara regions of the country. Black Sea region shares a border with Georgia, while Marmara region shares border with Greece and Bulgaria. The travel, transport and trade activities with these countries could transport alien species to the country (Wilson et al., 2016). The country has huge diversity in climate, which makes it suitable for the invasion of non-native 
species. Marmara region lies in western side of the country and has a moderate climate with average winter and summer temperature of $4{ }^{\circ} \mathrm{C}$ and $27^{\circ} \mathrm{C}$, respectively. Black Sea region is situated in eastern part of the country and has a wet, warm and humid climate with average winter and summer temperature of $7^{\circ} \mathrm{C}$ and $23^{\circ} \mathrm{C}$, respectively (Sensoy, 2014).

\section{Seed Collection}

Ragweed achenes (hereafter seeds) were collected from four different locations, two from Black Sea region (i.e., Samsun and Beşikduzu districts) and two from Marmara region (Keşan and Çorlu districts), which were highly infested with ragweed. Mature seeds were collected from 40-50 mother plants. The seeds spent 3 weeks in the laboratory, then were separated from the trash (leaves, inflorescence etc.) and stored in glass jars. The experiments were conducted immediately after the seed collection to avoid the effects of after-ripening on seed dormancy. The information on climatic features and geographic locations of the populations are presented in Table 1. Similarly, the climatic conditions prevailing at the seed collection sites of ragweed populations during ragweed growth season are provided in Table 2 .

Table 1: Geographic information and climatic conditions prevailing at the collection sites of different common ragweed populations in two distinct regions in Turkey

\begin{tabular}{|l|l|l|l|l|}
\hline Habitat & Agriculture & Ruderal & Roadside & $\begin{array}{l}\text { Agriculture and } \\
\text { Roadside }\end{array}$ \\
\hline Location & Beşikduzu & Samsun & Keşan & Çorlu \\
\hline Latitude & 41.05 & 41.38 & 41.09 & 41.14 \\
\hline Longitude & 39.21 & 36.21 & 26.64 & 27.87 \\
\hline Region & Black Sea & Black Sea & Marmara & Marmara \\
\hline $\begin{array}{l}\text { Aridity } \\
\text { Index }\end{array}$ & 1.11 & 0.89 & 0.68 & 0.67 \\
\hline PET (mm) & 779.30 & 813.58 & 901.24 & 839.18 \\
\hline $\begin{array}{l}\text { Annual } \\
\text { rainfall } \\
\text { (mm) }\end{array}$ & 865.42 & 723.60 & 614.66 & 563.81 \\
\hline \\
$\begin{array}{l}\text { Aridity } \\
\text { Class* }\end{array}$ & $\begin{array}{l}\text { Humid - No } \\
\text { risk of } \\
\text { desertification }\end{array}$ & $\begin{array}{l}\text { Semi humid } \\
\text { may be } \\
\text { vulnerable to } \\
\text { desertification }\end{array}$ & $\begin{array}{l}\text { Semi humid - } \\
\text { open to } \\
\text { desertification }\end{array}$ & $\begin{array}{l}\text { Semi humid- } \\
\text { open to } \\
\text { desertification }\end{array}$ \\
\hline
\end{tabular}

* Aridity class adopted from Camci et al. (2007), PET= potential evapotranspiration. 
Table 2: The climatic conditions prevailing at common ragweed populations during the growth seasons of the species

\begin{tabular}{|c|c|c|c|c|c|}
\hline \multirow[b]{2}{*}{ Growth phase } & & \multicolumn{2}{|c|}{ Eastern Populations } & \multicolumn{2}{|c|}{ Western Populations } \\
\hline & Months & Beşikduzu & Samsun & Keşan & Çorlu \\
\hline & \multicolumn{5}{|c|}{ Minimum Temperature ${ }^{\circ} \mathrm{C}$} \\
\hline \multirow[t]{2}{*}{ Germination } & May & 15.10 & 15.60 & 11.60 & 12.30 \\
\hline & June & 19.20 & 18.70 & 15.30 & 16.20 \\
\hline \multirow[t]{2}{*}{ Growth } & July & 21.70 & 19.40 & 17.90 & 15.80 \\
\hline & August & 22.40 & 21.70 & 18.80 & 18.00 \\
\hline \multirow[t]{3}{*}{ Seed set and dispersal } & September & 19.40 & 18.90 & 15.80 & 14.40 \\
\hline & October & 15.40 & 14.10 & 11.30 & 11.20 \\
\hline & \multicolumn{5}{|c|}{ Maximum Temperature ${ }^{\circ} \mathrm{C}$} \\
\hline \multirow[t]{2}{*}{ Germination } & May & 19.80 & 21.20 & 23.80 & 24.20 \\
\hline & June & 23.30 & 24.90 & 28.40 & 28.90 \\
\hline \multirow[t]{2}{*}{ Growth } & July & 25.30 & 27.20 & 30.90 & 31.00 \\
\hline & August & 25.70 & 27.30 & 30.60 & 30.80 \\
\hline \multirow[t]{3}{*}{ Seed set and dispersal } & September & 23.40 & 23.80 & 26.20 & 27.00 \\
\hline & October & 19.80 & 18.20 & 20.40 & 21.80 \\
\hline & \multicolumn{5}{|c|}{ Average Temperature ${ }^{\circ} \mathbf{C}$} \\
\hline \multirow[t]{2}{*}{ Germination } & May & 17.50 & 16.90 & 18.70 & 17.80 \\
\hline & June & 20.20 & 20.80 & 23.40 & 22.50 \\
\hline \multirow[t]{2}{*}{ Growth } & July & 22.50 & 23.30 & 25.90 & 24.90 \\
\hline & August & 23.00 & 23.50 & 25.70 & 24.90 \\
\hline \multirow[t]{2}{*}{ Seed set and dispersal } & September & 20.40 & 19.80 & 21.50 & 21.20 \\
\hline & October & 16.60 & 15.20 & 17.30 & 17.50 \\
\hline
\end{tabular}

\section{Presence/Absence of Seed Dormancy}

The presence/absence of seed dormancy in the tested populations was determined first. For this purpose, 50 seeds of each population in 5 replicates were placed on two layers of moistened filter paper in each of Petri dishes (5 Petri dishes for each population) having a diameter of $9 \mathrm{~cm}$. The Petri dishes were incubated at $25^{\circ} \mathrm{C}$ day and night temperature and in complete dark to avoid the effects of light on seed dormancy release. Filter papers were moistened with distilled water according to moisture needs of the seeds. Petri dishes were randomized daily to avoid the effects of temperature on the germination. Germination was observed 30 days after initiation of experiment. The nongerminating seeds were tested for viability using the crush test (Sawma and Mohler, 2002). The final germination percentage was converted to viability adjusted germination (VAG) using the equation 1 (Weller et al., 2016);

Viability Adjusted Germination (\%) $=\frac{\mathrm{N}_{\text {germ }}}{\mathrm{N}_{\text {germ }}+\mathrm{N}_{\text {viable _non _germ }}} \times 100$

Here,

$\mathrm{N}_{\text {germ }}=$ Total number of germinated seeds,

$\mathrm{N}_{\text {viable_non_germ }}=$ Total number of viable non-germinated seeds 
Seed Dormancy Release Experiments

Four different seed dormancy-breaking techniques along with non-treated control were tested to determine their possible role in overcoming dormancy of ragweed seeds and differences among populations arising from distinct climatic regions. The treatments were mechanical scarification with sandpaper, cold-wet stratification at $4^{\circ} \mathrm{C}$ for 2,3 and 4 weeks and a non-treated control. Seeds were placed between two layers of moistened filter paper, incubated at $4^{\circ} \mathrm{C}$ for 2,3 or 4 weeks in cold-wet stratification, surface dried and used in the experiments. Seeds were rubbed with sandpaper in mechanical scarification treatment and used in the experiment.

\section{Experimental Layout}

The experiment to infer the presence/absence of dormancy was laid in completely randomized design with five replications. Whereas seed dormancy release experiment was laid out in randomized complete block design with split plot arrangements. Ragweed populations were considered as main plots, whereas seed dormancy breaking techniques were randomized in sub-plots.

\section{General experimental procedure}

Five replicates of 50 seeds were used for each treatment, and seeds were placed on two layers of moistened filter paper in $9 \mathrm{~cm}$ Petri dishes. Petri dishes were moistened with deionized water according to the moisture requirements throughout the experiments. The Petri dishes were incubated at $25^{\circ} \mathrm{C}$ for 30 days, with 12 hours light and dark period. The light was supplied through cool, white fluorescent lamps in the incubators. The place of Petri dishes was changed daily to avoid any biased effects of the light/dark period on germination. The number of germinated seeds was counted daily and germinated seeds were removed from the Petri dishes. Different germination-related parameters were calculated from the collected data. Mean daily germination (MDG) was calculated by using the equation 2 (Czabator, 1962).

$$
\text { Mean Daily Germination }=\frac{\text { Total number of germinated Seeds }}{\text { Total number of days }}
$$

Similarly, germination speed (GS) was calculated through using equation 3 (Czabator, 1962)

$$
\text { Germination Speed }=\sum\left(\mathrm{n}_{1} / \mathrm{d}_{1}+\mathrm{n}_{2} / \mathrm{d}_{2}+\mathrm{n}_{3} / \mathrm{d}_{3}+\cdots \mathrm{n}_{\mathrm{n}} / \mathrm{d}_{\mathrm{n}}\right)(3)
$$

where, $n=$ Total number of germinated seeds; $d=$ Number of days $(1.2 .3 \ldots \ldots n)$

Finally, the final germination percentage at 30 days after initiation of the experiments was calculated as VAG by using equation (1).

Statistical Analysis

The germination data of the dormancy presence/absence were subjected to one-way analysis of variance (ANOVA), whereas a two-way ANOVA was conducted on seed dormancy breaking treatments to determine differences between populations and populations $\times$ dormancy breaking techniques' 
interactions. Least significant difference test at $99 \%$ probability was used to separate the means. All statistical computations were executed on SPSS statistical software version 23 (IBM, 2012). Microsoft Excel program was used for the graphical representation of data and computing standard errors.

\section{RESULTS AND DISCUSSION \\ Presence/Absence of Seed Dormancy}

The tested populations proved highly dormant and significant differences were observed in seed dormancy level of the tested populations (Figure 1). Seeds of the populations collected from Marmara region were more dormant (95.70\% and $96.71 \%$ dormancy in Keşan and Çorlu populations, respectively) compared with the seeds of populations collected from Black Sea region (Figure 1).

$$
\text { LSD } 0.01=1.67
$$

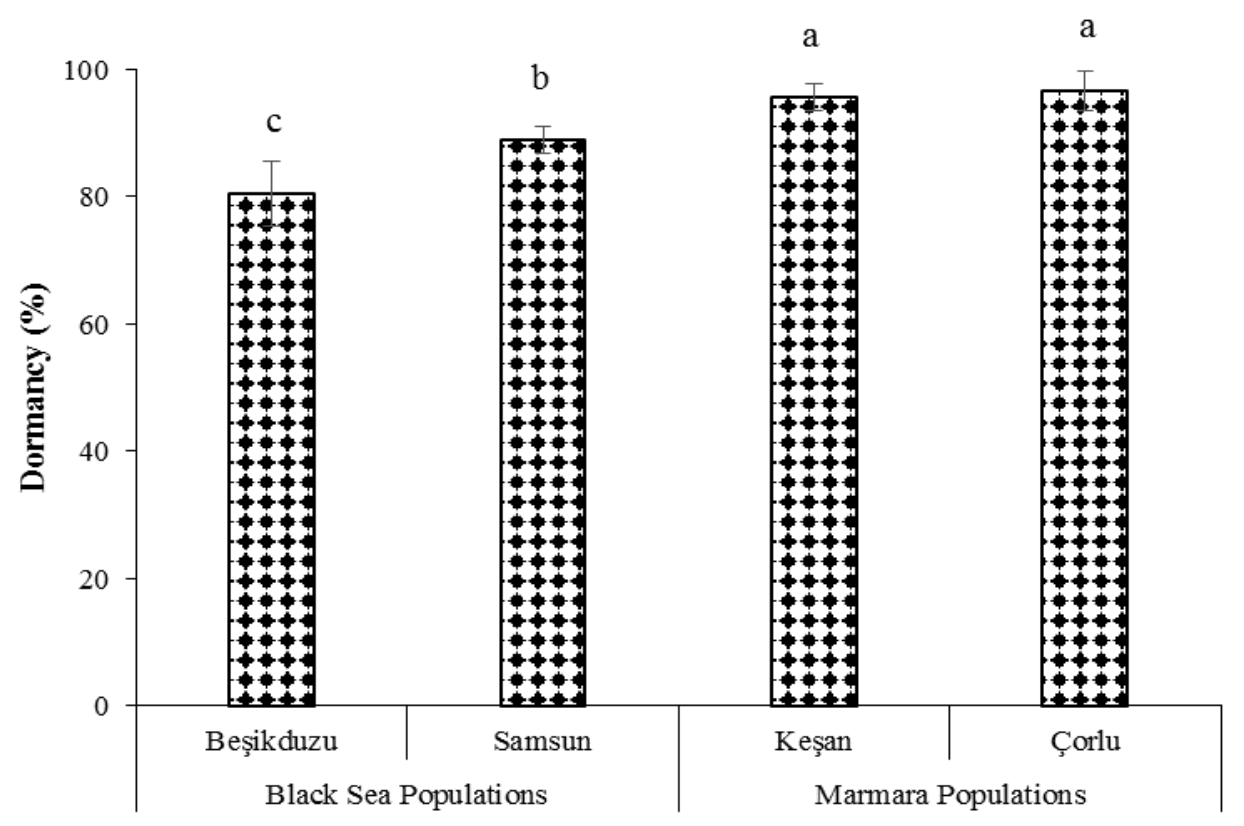

Figure 1: Dormancy level of different populations of common ragweed collected from two distinct climatic regions in Turkey, LSD = least significant difference.

\section{Seed Dormancy Release}

Significant differences were observed in ragweed populations, seed dormancy breaking techniques and populations $\times$ seed dormancy breaking techniques' interactions for final germination (VAG), time to complete $50 \%$ of total germination (T50) and mean daily germination (MDG) (Table 3). Cold-wet stratification stimulated the germination of all tested populations, while seeds of the populations collected from Marmara region required longer stratification time (4 weeks) in this regard (Figure 2). Germination of all populations was also 
stimulated by mechanical scarification and all populations responded similarly in this regard (Figure 2). Overall, the highest and lowest final germination was observed in cold-wet stratification for 4 weeks and non-treated seeds, respectively (Figure 2).

Table 3. Two-way Analysis of variance of common ragweed populations, seed dormancy breaking techniques and their interactions for viability-adjusted germination, mean daily germination and time to complete $50 \%$ germination of different common ragweed populations collected from two distinct regions in Turkey.

\begin{tabular}{|c|c|c|c|c|}
\hline \multicolumn{2}{|l|}{ Source } & Populations (P) & Techniques (T) & $\mathrm{P} \times \mathrm{T}$ \\
\hline \multicolumn{2}{|l|}{ DF } & 3 & 5 & 15 \\
\hline \multirow{3}{*}{ Sum of Squares } & VAG & 2185.44 & 73172.55 & 2015.73 \\
\hline & MDG & 0.15 & 5.08 & 0.14 \\
\hline & $\mathbf{T}_{50}$ & 27.26 & 1345.58 & 11.87 \\
\hline \multirow{3}{*}{ Mean Square } & VAG & 728.48 & 14634.51 & 183.25 \\
\hline & MDG & 0.05 & 1.02 & 0.01 \\
\hline & $\mathbf{T}_{50}$ & 9.09 & 269.12 & 1.08 \\
\hline \multirow{3}{*}{ F Value } & VAG & 39.72 & 797.94 & 9.99 \\
\hline & MDG & 39.72 & 797.94 & 9.99 \\
\hline & $\mathbf{T}_{50}$ & 13.67 & 404.75 & 1.62 \\
\hline \multirow{3}{*}{ P Value } & VAG & $<0.0001$ & $<0.0001$ & $<0.0001$ \\
\hline & MDG & $<0.0001$ & $<0.0001$ & $<0.0001$ \\
\hline & $\mathbf{T}_{50}$ & $<0.0001$ & $<0.0001$ & 0.0071 \\
\hline
\end{tabular}

$\mathrm{DF}=$ degree of freedom, $\mathrm{VAG}=$ Viability adjusted germination (final germination), $\mathrm{MDG}=$ Mean daily germination, $\mathrm{T}_{50}=$ Time to complete $50 \%$ of the total germination, $*=$ significant at $1 \%$ level of significance, ns= non-significant 


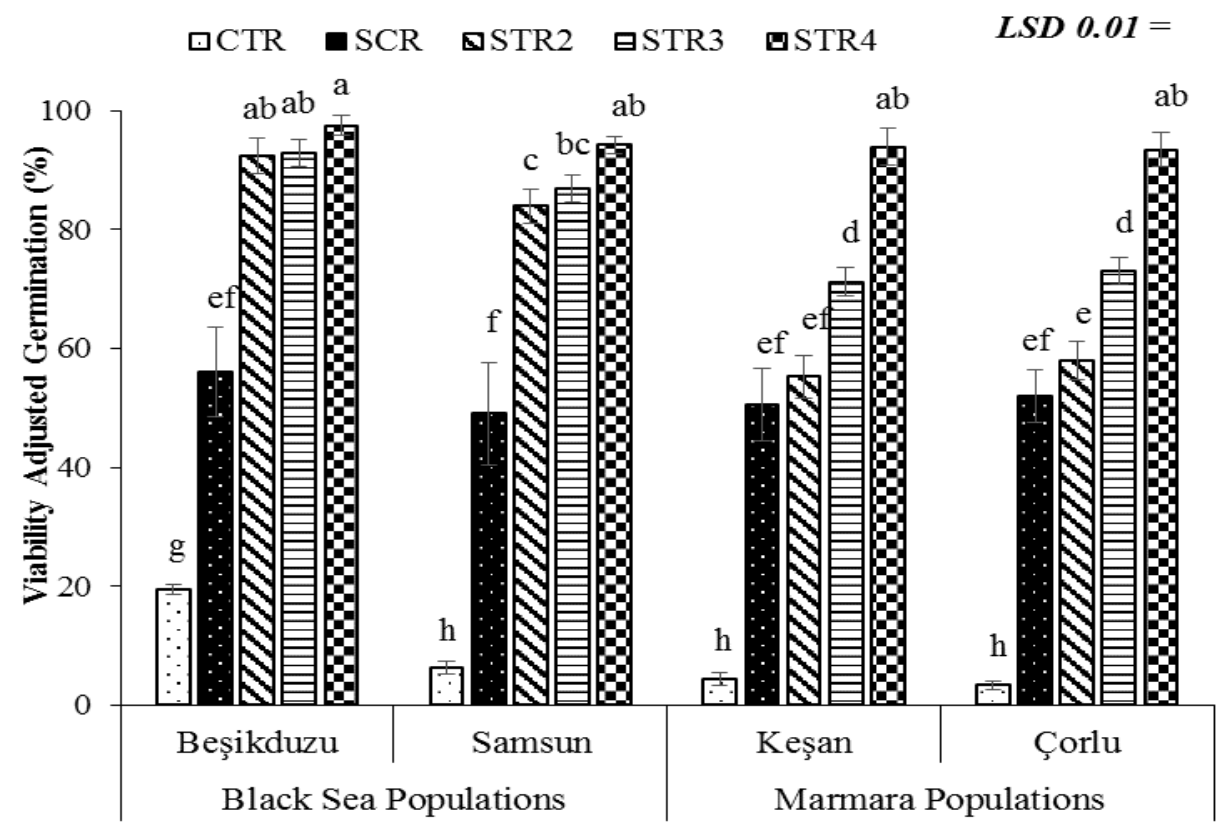

Figure 2: Effect of different seed dormancy breaking techniques on final germination percentage of different populations of common ragweed collected from two distinct climatic regions in Turkey, CTR=non-treated seeds, $\mathrm{SCR}=$ mechanical scarification with sandpaper, STR2=cold-wet stratification for 2 weeks, STR3=cold-wet stratification for 3 weeks and STR4=cold-wet stratification for 4 weeks, LSD=least significant difference, The vertical bars show standard error of means and any two means sharing common letter are statistically not different at $\mathrm{p} \leq 0.01$.

The increasing duration of cold-wet stratification not only stimulated the germination, but also decreased the time to $50 \%$ germination (Figure 3). The highest number of days to $\mathrm{T}_{50}$ were taken by control treatment, while the lowest days for $\mathrm{T}_{50}$ were taken by cold-wet stratification for 4 weeks. The seeds of the populations collected from Marmara region took longer time to reach $T_{50}$, whereas seeds of the populations collected from Black Sea region reached to $\mathrm{T}_{50}$ in relatively less time for in all seed dormancy breaking techniques (Figure 3).

Mean daily germination was improved by increasing duration of cold-wet stratification in the similar manner as of final germination percentage (Figure 4). The seeds of the populations collected from Marmara region had less MDG compared to the seeds of populations collected from Black Sea region in all seed dormancy breaking techniques except cold-wet stratification for 4 weeks, where all populations behaved similarly (Figure 4). The highest and lowest MDG was observed in cold-wet stratified seeds for 4 weeks of all populations and nontreated seeds, respectively (Figure 4). 
Seed dormancy is an important adaptive trait allowing invasive plant species to explore novel environments for range expansion. Significant differences were observed in seed dormancy level of different ragweed populations arising from distinct climatic regions. The differences in seed dormancy level can be attributed to different climatic conditions prevailing in different regions at the time of seed set (Sensoy, 2014). Ecological adaptations of the species for persisting in different geographic regions might be the other reason for differences among seed dormancy level in different populations of the species (Essl et al., 2015).

Cold-wet stratification for different durations was the most effective technique for overcoming seed dormancy of all populations. However, populations significantly differed for stratification time for effective release of seed dormancy. Mechanical scarification also released seed dormancy to significant extent, however it cannot be considered akin to cold-wet stratification. Mechanical scarification probably helped the seeds to overcome the mechanical resistance offered by the seed coat to weak embryo, thus resulted in better germination.

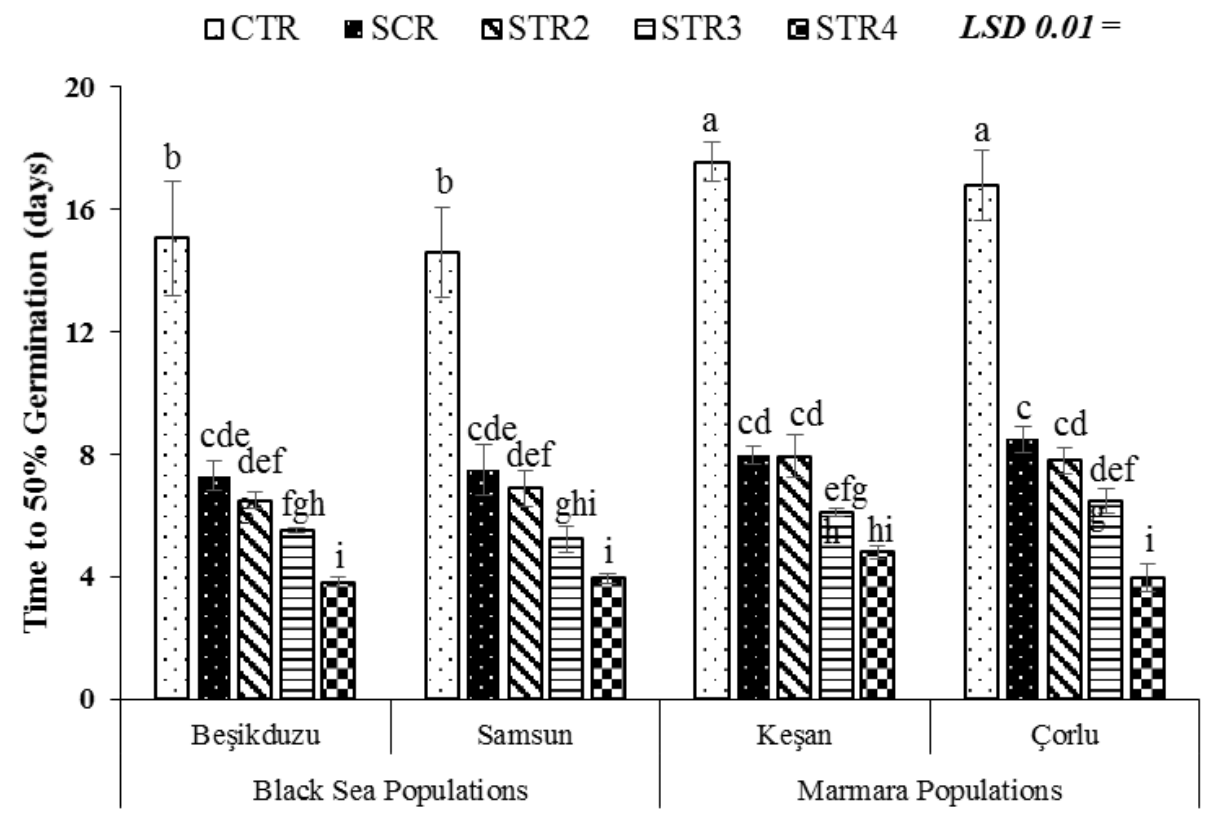

Figure 3: Effect of different seed dormancy breaking techniques on time to 50\% germination of different populations of common ragweed collected from two distinct climatic regions in Turkey, CTR=non-treated seeds, SCR=mechanical scarification with sandpaper, STR2=cold-wet stratification for 2 weeks, STR3=cold-wet stratification for 3 weeks and STR4=cold-wet stratification for 4 weeks, LSD=least significant difference, The vertical bars show standard error of means and any two means sharing common letter are statistically not different at $\mathrm{p} \leq 0.01$. 


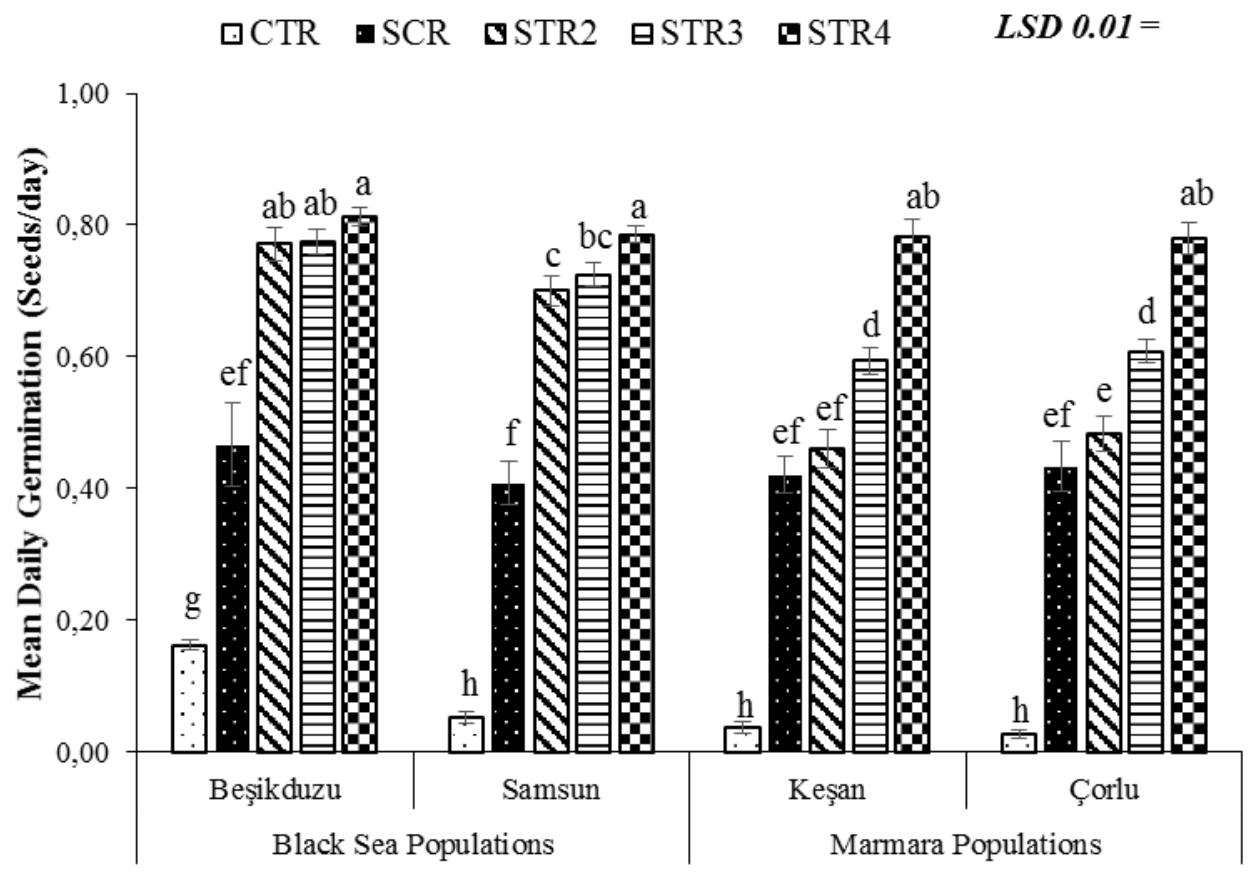

Figure 4: Effect of different seed dormancy breaking techniques on mean daily germination of different populations of common ragweed collected from two distinct climatic regions in Turkey, CTR=non-treated seeds, $S C R=$ mechanical scarification with sandpaper, STR2=cold-wet stratification for 2 weeks, STR3=cold-wet stratification for 3 weeks and STR4=cold-wet stratification for 4 weeks, LSD=least significant difference, The vertical bars show standard error of means and any two means sharing common letter are statistically not different at $\mathrm{p} \leq 0.01$

Ragweed can successfully persist in a wide range of habitat and ecological conditions (Essl et al., 2015). Different ragweed populations significantly differed for germination in response to different salinity levels (DiTommaso, 2004). Differences in the germination of different populations of weedy species have been widely cited in different studies (Li and Feng, , 2009; Eslami, 2011). However, some studies also reported that different populations of ragweed show similar germination and dormancy (Dinelli et al., 2013). These findings suggest that ragweed seeds undergo regional adaptations to explore novel environments.

Seed dormancy allows the species to persist in the soil seed bank, and breaking of dormancy while overwintering ensures seed germination in the next growing season. The efficacy of cold-wet stratification in breaking dormancy is directly linked with the germination timing of ragweed at the beginning of the growing season. Several authors have reported that cold stratification for different time periods ( 2 to 8 weeks) at $4^{\circ} \mathrm{C}$ effectively breaks the dormancy of ragweed seeds (Willemsen and Rice, 1972; Pickett and Baskin, 1973; Baskin and Baskin, 
1980; Fumanal et al., 2006; Essl et al., 2015). Cold-wet scarification requirements for breaking seed dormancy of ragweed correspond well to its distribution range in Turkey as well as across the whole Europe (Essl et al., 2015; Ozaslan et al., 2016). The results also reveal that ragweed requires a specific set of environmental conditions for germination; however, cold-wet stratification for 2 weeks, even did not completely (100\% germination) overcome the dormancy and populations required more than 2 weeks of cold-wet stratification for complete release of seed dormancy. The possible reasons of population differences might be the maturity time of the seeds and environmental conditions prevailing at the time of seed maturation. Earlier studies have confirmed that seed collected from different populations of same weeds at different times exhibit significant differences for dormancy (Steadman et al., 2004). Since seeds were collected at same time, the population differences could not be attributed to seed maturation timing.

Ragweed flowers and matures at different times in different geographic regions in Turkey (Author's observation). The species germinates and matures earlier in the Marmara region compared with Black Sea region. Climatic conditions of these regions can be considered as the sole driver of these differences. The differences in the stratification time requirement could be attributed to different maturation timings and ecological adaptations of the species in distinct geographic regions. Stratification requirements could be used to predict the germination timing in different regions and could aid in implementation of management practices.

\section{CONCLUSIONS}

The current study concludes that different ragweed populations collected from different climatic regions exhibit significant differences for seed dormancy. Cold-wet scarification successfully overcomes the dormancy, while populations from different climatic regions require different cold-wet stratification duration for complete seed dormancy release. The results of the current study add valuable information on the understanding of ecology of different populations distributed in distinct climatic regions of the country. Moreover, biological changes in the seeds and embryo growth after mechanical scarification need to be explored for better understanding of the phenomenon of dormancy release by mechanical scarification. Nonetheless, a thorough understanding of the germination biology of regional populations is necessary for successful management of ragweed at regional scales.

\section{ACKNOWLEDGEMENTS}

The current study was funded by the Scientific and Technological Council of Turkey (TUBITAK) with a Grant Number 113 O 790 as a part of the COST Action (TD 1209 - European Information System for Alien Species). 


\section{REFERENCES}

Baskin JM, Baskin CC. 1980. Ecophysiology of secondary dormancy in seeds of Ambrosia artemisiifolia. Ecology, 61: 475-480.

Batlla D, Benech-Arnold RL. 2007. Predicting changes in dormancy level in weed seed soil banks: implications for weed management. Crop Protection, 26(3): 189-197.

Batlla D, Kruk BC and Benech-Arnold RL. 2004. Modelling changes in dormancy in weed soil seed banks: implications for the prediction of weed emergence. In: Benech-Arnold R.L., Sánchez R.A. (eds.): Handbook of seed physiology. Applications to agriculture. New York: Haworth Press Inc: 245-264.

Bazzaz F. 1970. Secondary dormancy in the seeds of the common ragweed Ambrosia artemisiifolia. Bulletin of the Torrey Botanical Club, 302-305.

Brownsey RN, Kyser GB and DiTomaso JM. 2013. Seed and germination biology of Dittrichia graveolens (Stinkwort). Invasive Plant Science and Management, 6(3): 371-380.

Camci CS, Karaca A, Haktanır K and Yildiz H. 2007. Global attention to Turkey due to desertification. Environmental Monitoring and Assessment, 128: 489-493.

Celenk S, Malyer H. 2017. The occurrence of Ambrosia pollen in the atmosphere of Northwest Turkey: investigation of possible source regions. International Journal of Biometeorology, 1-12.

Czabator FJ. 1962. Germination value: an index combining speed and completeness of pine seed germination. Forest Science, 8: 386-396.

Delivering Alien Invasive Species Inventories for Europe - DAISIE. 2016. 100 of the Worst: http:// www.europe-aliens.org/speciesTheWorst.do (accessed 3.7.3017).

Dinelli G, Marotti I, Catizone P, Bosi S, Tanveer A, Abbas R and Pavlovic D. 2013. Germination ecology of Ambrosia artemisiifolia L. and Ambrosia trifida L. biotypes suspected of glyphosate resistance. Open Life Sciences, 8: 286-296.

DiTommaso, A. 2004. Germination behavior of common ragweed (Ambrosia artemisiifolia) populations across a range of salinities. Weed Science, 52: 1002-1009.

Ellis R, Roberts E. 1981. The quantification of ageing and survival in orthodox seeds. Seed Science and Technology, 9: 373-409.

Eslami, S. 2011. Comparative germination and emergence ecology of two populations of common lambsquarters (Chenopodium album) from Iran and Denmark. Weed science, 59: 90-97.

Essl F, Biró K, Brandes D, Broennimann O, Bullock JM, Chapman DS, Chauvel B, Dullinger S, Fumanal B and Guisan A. 2015. Biological flora of the British Isles: Ambrosia artemisiifolia. Journal of Ecology, 103: 1069-1098.

Farooq S, Lommen STE, Hallmann CA and Onen H. 2016. Seed and pollen production variations among Ragweed populations in Black Sea region. In: Book of Abstracts. Turkey $6^{\text {th }}$ Plant Protection Congress with International Participation, Konya, Turkey, September 5-8, 2016.

Fumanal B, Girod C, Fried G, Bretagnolle F and Chauvel B. 2008. Can the large ecological amplitude of Ambrosia artemisiifolia explain its invasive success in France? Weed Research, 48: 349-359.

Fumanal B, Plenchette C, Chauvel B and Bretagnolle F. 2006. Which role can arbuscular mycorrhizal fungi play in the facilitation of Ambrosia artemisiifolia L. invasion in France? Mycorrhiza, 17: 25-35.

Gioria M, Pyšek P. 2017. Early bird catches the worm: germination as a critical step in plant invasion. Bioogical Invasions, 19(4): 1055-1080. 
IBM Corporation. (2012): IBM SPSS statistics for Windows, version 21.0. IBM Corporation Armonk, NY.

Li YP, Feng YL. 2009. Differences in seed morphometric and germination traits of crofton weed (Eupatorium adenophorum) from different elevations. Weed Science, 57: 26-30.

Mandak B, Pyšek P. 2001. Fruit dispersal and seed banks in Atriplex sagittata: the role of heterocarpy. Journal of Ecology, 89: 159-165.

Onen H, 2015. Invasive plants catalogue of Turkey. Ankara, Turkey: Ministry of Food, Agriculture and Livestock. Ankara Turkey. ISBN: 978-605-9175-05-0. In Turkish.

Onen H, Gunal H and Ozcan S. 2014. The Black Sea highway: the route of common ragweed (Ambrosia artemisiifolia L.) invasion in Turkey. In: Book of Abstracts: $8^{\text {th }}$ International Conference on Biological Invasions from understanding to action, Antalya, Turkey, November 3-8, 2014.

Onen H, Ozaslan C and Akyol N 2015. Ambrosia artemisiifolia L. In: Onen H. (eds): Invasive Plants Catalogue of Turkey. ISBN: 978-605-9175-05-0. In Turkish.

Onen H, Farooq S, Gunal H and Ozaslan C. 2016. Common ragweed invasion in Turkey: What we have learnt so far? In: Book of Abstracts. Turkey $6^{\text {th }}$ Plant Protection Congress with International Participation, Konya, Turkey, September 5-8, 2016.

Onen H, Farooq S, Gunal H, Ozaslan C and Erdem H. 2017. Higher tolerance to abiotic stresses and soil types may accelerate common ragweed (Ambrosia artemisiifolia) Invasion. Weed Science, 65(1): 115-127.

Ozaslan C, Onen H, Farooq S, Gunal H and Akyol N. 2016. Common ragweed: An emerging threat for sunflower production and human health in Turkey. Weed Biology and Management, 1: 42-55.

Pickett ST, Baskin JM. 1973. The role of temperature and light in the germination behavior of Ambrosia artemisiifolia. Bulletin of the Torrey Botanical Club, 100: $165-170$.

Richardson DM, Kluge RL. 2008. Seed banks of invasive Australian Acacia species in South Africa: role in invasiveness and options for management. Perspectives in Plant Ecology, Evolution and Systematics, 10: 161-177.

Sawma JT, Mohler CL. 2002. Evaluating seed viability by an unimbibed seed crush test in comparison with the tetrazolium test 1. Weed Technology, 16: 781-786.

Sensoy, S. 2014. Climate of Turkey: http://topraksuenerji.org/Climate_of_turkey.pdf (accessed 3.7.2017).

Steadman KJ, Ellery AJ, Chapman R, Moore A and Turner NC. 2004. Maturation temperature and rainfall influence seed dormancy characteristics of annual ryegrass (Lolium rigidum). Crop and Pasture Science, 55: 1047-1057.

Weller S, Florentine S, Sillitoe J, Grech C and McLaren D. 2016. An investigation of the effects of stage of ensilage on Nassella neesiana seeds, for reducing seed viability and injury to livestock. Scientific reports, 6. doi:10.1038/srep22345.

Willemsen RW, Rice EL. 1972. Mechanism of seed dormancy in Ambrosia artemisiifolia. American Journal of Botany, 59(3): 248-257.

Wilson JRU, García-Díaz P, Cassey P, Richardson DM, Pyšek P and Blackburn TM. 2016. Biological invasions and natural colonisations are different: the need for invasion science. NeoBiota, 31: 87-98.

Zemmer F, Karaca F and Ozkaragoz F. 2012. Ragweed pollen observed in Turkey: detection of sources using back trajectory models. Science of the Total Environment, 430, 101-108. 